\title{
Anti-cancerous/Anti-bacterial Activities of Allicin Generated In situ from Diastereo Pure Alliins by Alliinase
}

\author{
Shalini Gupta ${ }^{1}$, Lasanthi Jayathilaka ${ }^{1}$, Jin-Sheng Huang ${ }^{1}$, Jenny Lee ${ }^{2}$ \\ and Bao-Shiang Lee ${ }^{1^{*}}$ \\ ${ }^{1}$ Protein Research Laboratory, Research Resources Center, University of Illinois at Chicago, \\ 835 S. Wolcott Avenue, Chicago, IL 60612, USA. \\ ${ }^{2}$ Department of Chemical Engineering, Columbia University, 500 W. $120^{\text {th }}$ Street, New York, \\ NY 10027, USA.
}

Authors' contributions

This work was jointly carried out in collaboration between all authors. All authors read and approved the final manuscript.

Article Information

DOI: $10.9734 / I J B C R R / 2015 / 19522$

Editor(s):

(1) Chunying Li, Department of Biochemistry and Molecular Biology Wayne State University, School of Medicine, Detroit,

USA.

Reviewers:

(1) Daniela Hanganu, Department of Pharmacognosy, "luliu Hatieganu" University of Medicine and Pharmacy, Romania.

(2) Tülay Aşkin Çelik, Department of Biology, Adnan Menderes University, Aydin, Turkey. Complete Peer review History: http://sciencedomain.org/review-history/10162

Original Research Article

Received $14^{\text {th }}$ June 2015

Accepted $2^{\text {nd }}$ July 2015

Published 14 ${ }^{\text {th }}$ July 2015

\section{ABSTRACT}

Aims: To facilitate allicin generation in-situ from pure diastereomers of alliin by enzymatic reaction of alliinase and assess its anti-cancerous/anti-bacterial activities.

Study Design: Chemical synthesis and in-vitro assay of anti-cancerous/anti-bacterial activities.

Place and Duration of Study: Protein Research Laboratory, Research Resources Center, University of Illinois at Chicago, between February 2014 and February 2015.

Methodology: Cancer cell viability assay MTT assay, bacterial plate-diffusion growth inhibition assay, and flow cytometry cell cycle analysis have been used to demonstrate the anticancerous/anti-pathogen activities of the in-situ allicin. Diastereomers of alliin are produced by $\mathrm{H}_{2} \mathrm{O}_{2}$ oxidation of deoxyalliin, which is prepared by mixing L-cysteine and allyl bromide. Deoxyalliin and diastereomers of alliin are purified to high purity with repeated fractional crystallization. In 
addition, fluorenylmethyloxycarbonyl (Fmoc) protected alliin and alliin methyl ester are synthesized and purified with RP-HPLC to test the importance of amino and carboxyl groups of alliin in alliinase enzymatic reaction. Alliinase is produced by a simple and effective method from an aqueous garlic extract

Results: Results from spectrophotometric alliinase activity assay indicate that (+)-L-alliin is more reactive toward alliinase than (-)-L-alliin, and both amino and carboxyl groups of the cysteine portion of alliin are critical in alliinase enzymatic reaction. Results from cancer cell viability assay MTT assay, bacterial plate-diffusion growth inhibition, and flow cytometry cell cycle analysis confirm that the in-situ allicin is as active as allicin purified from aqueous garlic extract or allicin synthesized chemically in a dose-dependent manner.

Conclusion: We describe here facile pathways to synthesize diastereomerically pure alliins and isolate allinase. The in-situ allicin conversed from alliin by allinase is very active. The data obtained here provide useful information on the design of the in-situ allicin strategy.

Keywords: Allium sativum; alliin; allicin; alliinase; anti-cancerous; anti-bacterial.

\section{ABBREVIATIONS}

AGE, Aqueous Garlic Extract; MTT, 3-(4,5-Dimethylthiazol-2-yl)-2,5-diphenyltetrazolium bromide; SDS-PAGE, sodium dodecyl sulfate polyacrylamide gel electrophoresis.

\section{INTRODUCTION}

Allicin protects garlic from pests, insects, and microorganisms [1-3]. It has lipid-lowering, antiblood coagulation, anti-hypertension, antithrombotic, anti-inflammatory, anti-oxidant, anticancerous, anti-viral, anti-microbial, and antiparasitic activities with low toxicity towards human [2-4]. Not surprisingly, garlic is the bestselling herbal supplements in the United States and allicin has been explored as a potential lead compound for drug design [5,6]. Allicin is formed by the action of the enzyme alliinase on alliin. Purified allicin is unstable with a characteristic smell of garlic [7-9]. It decomposes into biologically less active oil-soluble organosulfur compounds (OSCs) such as diallyl sulfide, diallyl disulfide, diallyl trisulfide (allitridi), dithiins, and ajoene and some water-soluble OSCs such as Sallyl cysteine and S-allyl mercaptocysteine [10-12]. Allicin reacts rapidly with free thiol groups $[13,14]$. As soon as allicin is taken up by the body or is in the circulatory system, it reacts with accessible thiol groups, penetrating biological membranes and decomposing to other compounds. Therefore it disappears from the circulation within a few minutes after injection [13-15]. This is why the majority of the potent anti-cancerous/anti-bacterial activities effects of allicin were demonstrated in vitro and makes a pharmaceutical application of allicin implausible $[4,8,16]$.

However, the usage of allicin in medical areas mentioned above remains an attractive endeavor. In recent years there has been a growing interest of circumventing the instability of allicin by use a binary system consisting of the plant enzyme alliinase and its substrate alliin to generate allicin in situ [4,17-19]. In this binary system, the two inactive stable components generate an active compound that exhibit biological activity in situ. In one proof-of-concept study, alliinase is conjugated to an anti-CD20 antibody rituximab which successfully inhibits the proliferation of $\mathrm{CD} 20+\mathrm{B}$ chronic lymphocytic leukemia via allicin produced from alliin in situ [18]. It is therefore possible to initiate biological activity in a controlled, effective manner. Apart from circumventing the instability of allicin, this binary system has additional advantages, such as low toxicity of its individual components and site-directed selective activation. Furthermore, alliinase is able to react besides alliin other Salk(en)yl-L-cystene solfoxides such as dihydroalliin, S-isopropyl-L-cysteine sulfoxide, and S-butyl-L-cysteine sulfoxide [20]. In general, substrates of allinase reaction contain the following structural features: (1) They must be derivatives of cysteine. (2) The sulfur atom of the cysteine derivative must link to alk(en)yl group. (3) The amino group of the cysteine portion of the compound must not be blocked. (4) The sulfur atom of the cysteine derivative must be a sulfoxide. These observations pave the way to a range of novel binary systems with specific chemical and biochemical properties.

In situ allicin has shown promising applications in vivo. However, more information on reagent 
preparation and reaction conditions are needed to realize the biomedical potential of in situ allicin strategy. For example, there is lack of information on the efficacy of in situ allicin systems produced from pure diastereomers or derivatives of alliin. Here we developed a facial synthesis for mass production of diastereo pure alliins to alleviate the need of purchasing expensive alliin, an effective method of purifying alliinase, and simple methods of assessing the efficacy of the in situ allicin. In addition, the inactivity of fluorenylmethyloxycarbonyl (Fmoc) protected alliin and alliin methyl ester in alliinase enzymatic reaction enable us to conclude that the amino and carboxyl moieties of alliin are critical for alliinase reaction. Results indicate that the length of alliin in cancer cell culture before addition of alliinase is most effective within 3 days and ineffective after 7 days as a substrate of the enzymatic reaction of alliinase. In addition, allinase reacts less with (-)-L- alliin than with (+)L- alliin. Cancer cell viability assay MTT assay, alliinase assay, bacterial plate-diffusion growth inhibition assay, and flow cytometry cell cycle analysis are effective in validating the anticancerous/anti-pathogen activities of the in-situ allicin.

\section{MATERIALS AND METHODS}

\subsection{Materials}

All reagents and solvents were obtained from Sigma-Aldrich Chemical (St. Louis, MO, USA) with the highest purity available and used without further purification. Allicin was prepared from either aqueous garlic extract or by $\mathrm{H}_{2} \mathrm{O}_{2}$ oxidation of allyl disulfide with HPLC purification as previously described $[8,9]$. Double distilled water was used throughout the experiments. Staphylococcus aureus subsp. aureus Rosenbach (ATCC $\circledast 6538^{\mathrm{TM}}$ ) and Escherichia coli (Migula) Castellani and Chalmers (ATCC $\AA$ $8739^{\mathrm{TM}}$ ) were from ATCC (Manassas, VA, USA). PD10 desalting column packed with Sephadex G-25 medium (GE Healthcare Biosciences, Piscataway, NJ, USA) was used to separate lowmolecular weight $(<1000 \mathrm{Da})$ from highmolecular weight (> $5000 \mathrm{Da}$ ) biomolecules. ${ }^{1} \mathrm{H}$ and ${ }^{13} \mathrm{C}$ nuclear magnetic resonance (NMR) spectra were recorded on a Bruker FT-NMR spectrometer (Billerica, MA, USA) at 900 and $225 \mathrm{MHz}$, respectively. The $\mathrm{nmr}$ spectra were measured in $\mathrm{D}_{2} \mathrm{O}$ or $\mathrm{CD}_{3} \mathrm{CN}$ at $25^{\circ} \mathrm{C}$ and the ${ }^{1} \mathrm{H}$ and ${ }^{13} \mathrm{C}$ chemical shift values $(\delta)$ were reported in parts per million (ppm) relative to the TSP $(\delta$ $0.0 \mathrm{ppm})$ and DMSO (ठ $39.5 \mathrm{ppm})$, respectively.
Coupling constants ( $\mathrm{J}$ values) were given in $\mathrm{Hz}$. Multiplicities are reported as follows: $\mathrm{s}=$ singlet, $\mathrm{d}=$ doublet, $\mathrm{dd}=$ doublet of doublets, $\mathrm{t}=$ triplet, $\mathrm{td}=$ triplet of doublets, $\mathrm{tt}=$ triplet of triplets, $\mathrm{q}=$ quartet, $\mathrm{dq}=$ doublet of quartet. Accurate mass measurements (ESI-HRMS) were recorded on a LC-MS IT-TOF (Ion Trap-Time of Flight) mass spectrometry (Shimadzu Scientific Instruments, Columbia, MD, USA). Resolution was set between 5000 and 10000. It delivered high mass accuracy and high mass resolution independent of MS mode with a dual source and a suitable external calibrant. Thin-layer chromatography was carried out on aluminum-backed $0.25-\mathrm{mm}$ silica gel plates with fluorescence indicator (Dynamic Adsorbents, Norcross, GA, USA) and were developed with n-butanol: glacial acetic acid:water $(2: 1: 1, \mathrm{v} / \mathrm{v} / \mathrm{v})$. Substance spots on the chromatographic plate were detected by illumination with UV light (254 nm), KMnO4 staining, or $0.5 \%$ ninhydrin solution spraying. Reaction products of Fmoc protected alliin and alliin methyl ester were purified using either a Perseptive Biosystems (Life Technologies, Carlsbad, CA, USA) or an Agilent (Agilent Technologies, Santa Clara, CA, USA) HPLC system with a Phenomenex (Torrance, CA, USA) Kinetex Reversed-Phase C18 $150 \times 2.1 \mathrm{~mm}$ or 250 x $4.6 \mathrm{~mm}$ column. Gradient elution was run using solvents $A$ and $B$ (solvent $A: 0.1 \%$ TFA in water; solvent $B$ : $0.1 \%$ TFA in acetonitrile) from $100 \% \mathrm{~A}$ for $5 \mathrm{~min}$ and then to $100 \% \mathrm{~B}$ for another 20 min by linearly increasing solvent B. UV absorbance at $220 \mathrm{~nm}$ or $260 \mathrm{~nm}$ was used as detection. The progress of the reaction was monitored by RP-HPLC. ${ }^{1} \mathrm{H}$ NMR spectrum in an appropriate deuterium solvent of the resultant reaction solution confirmed completion of the reaction. The products were confirmed by TLC, melting point, and spectroscopic $\left({ }^{1} \mathrm{H},{ }^{13} \mathrm{C}\right.$ 1-D or 2-D NMR and HRMS-ESI) analysis. Yields refer to chromatographic and spectroscopic pure compounds, second level heading.

\subsection{Preparation of Aqueous Garlic Extract}

Garlic extract was prepared from garlic cloves as in previously described protocol with modifications [8,9]. Briefly, garlic (The Garlic Company, Bakersfield, CA, USA) was purchased from the Costco Wholesale Corporation at Naperville (Naperville, IL, USA) and the aqueous garlic extract (AGE) was prepared from peeled garlic cloves in hepes buffer $(50 \mathrm{mM}, \mathrm{pH} 7.2)$ containing $10 \%$ glycerol, $1 \mathrm{mM} \mathrm{CaCl} 2,1 \mathrm{mM}$ $\mathrm{MnCl} 2,1 \mathrm{mM} \mathrm{MgCl} 2,20 \mathrm{uM}$ pyridoxal 5'phosphate, and $0.25 \mathrm{M} \mathrm{NaCl}$ at $1 \mathrm{~g} / \mathrm{mL}$. A $900 \mathrm{~W}$ 
high-torque motor blender (NutriBullet 900, Los Angeles, CA) was used to crush and pulverize the garlic cloves using three 5-second pulses with 2-minute breaks between pulses at $4^{\circ} \mathrm{C}$. The garlic puree was strained through 3 layers of cheesecloth. The filtrate was kept overnight at $20^{\circ} \mathrm{C}$. The following day, AGE was spun at 9878 $\mathrm{xg}$ for 4 minutes at $4^{\circ} \mathrm{C}$. Finally, the supernatant was filtered through a sterilized $0.22 \mu \mathrm{m}$ syringedriven filter (Becton Drive, Franklin Lakes, NJ, USA) to remove any residual precipitate and to sterilize the AGE. The clear supernatant was aliquoted and stored at $-80^{\circ} \mathrm{C}$ until use.

\subsection{Alliinase Purification Characterization}

The enzyme allinase was purified to at least 95\% homogeneity using PD10 and gel-filtration columns. Briefly, $2.5 \mathrm{~mL}$ of AGE was loaded onto a PD10 column. High-molecular weight $(>5000$ Da) biomolecules eluted into the first $3.5 \mathrm{~mL}$ fraction and low-molecular weight compounds into next $5 \mathrm{~mL}$ fraction with hepes buffer $(50 \mathrm{mM}$, $\mathrm{pH}$ 7.2) containing $10 \%$ glycerol, $1 \mathrm{mM} \mathrm{CaCl} 2,1$ $\mathrm{mM} \mathrm{MnCl2,} 1 \mathrm{mM} \mathrm{MgCl2}, 20$ uM pyridoxal 5'phosphate, and $0.25 \mathrm{M} \mathrm{NaCl}$. Subsequently, 2 $\mathrm{mL}$ of the first $3.5 \mathrm{~mL}$ PD10 protein fraction was injected onto Phenomenex (Torrance, CA, USA) Yarra $3 \mu \mathrm{m}$ gel-filtration $300 \times 7.8 \mathrm{~mm}$ HPLC column and the column was developed using hepes buffer at a flow rate of $1 \mathrm{~mL} / \mathrm{min}$ and 280 $\mathrm{nm}$ detection. Pure alliinase fraction was collected at 8 min which was verified by alliinase enzyme activity assay and mass spectrometry. Concentration of alliinase was measured by $1-D$ sodium dodecyl sulfate polyacrylamide gel electrophoresis (SDS-PAGE) band intensity using BSA as standard. The alliinase solution displayed a single protein band ( $52 \mathrm{kDa})$ on 1-D SDS-PAGE containing $4-12 \% \quad(w / v)$ polyacrylamide (Invitrogen, Carlsbad, CA) with MES running buffer and stained with Coomassie blue.

The enzyme activity assay of alliinase was determined by the spectrophotometric assay using 4-mercaptopyridine (4-MP) method in a cell free system according to Miron et al. [21] with modifications. The assay is based on the assessment of the production rate of allicin using alliin as subtract. One enzyme unit is defined as the amount of enzyme necessary to convert alliin into $1 \mu \mathrm{mol}$ pyruvate per minute. The molar consumption of 4-MP in its reaction with allicin is equivalent to the production of pyruvic acid. One $\mathrm{mL}$ of the reaction solution contained 4-MP $\left(10^{-4} \mathrm{M}\right)$ in $50 \mathrm{mM}$ sodium phosphate, $2 \mathrm{mM}$ EDTA, $0.02 \mathrm{mM}$ pyridoxal 5'-phosphate, $200 \mu \mathrm{g}$ alliin $(1.12 \mathrm{mM})$, and $20 \mu \mathrm{g}$ alliinase $(0.36 \mu \mathrm{M})$, $\mathrm{pH}$ 7.2. Enzymatic activity started upon addition of $20 \mu \mathrm{L}$ alliinase $(1 \mathrm{mg} / \mathrm{mL}$ solution in hepes buffer, $18 \mu \mathrm{M}$ ). Enzymatic activity was monitored at room temperature by the initial rate of the decrease in UV light absorption at $324 \mathrm{~nm}$ over a period of $5 \mathrm{~min}$ using quartz cuvettes of $1 \mathrm{~cm}$ in path length and a Spectronic Genesys UV/Vis spectrometer (Thermo Spectronic, Rochester, NY, USA). One unit of enzyme activity was defined as releasing $1 \mu \mathrm{mol}$ pyruvate per minute and calculated using molar absorptivity $\varepsilon_{324}=$ $19,800 \mathrm{M}^{-1} \mathrm{~cm}^{-1}$.

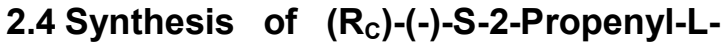 Cysteine (3) (L-Deoxyalliin)}

The synthesis of compound 3 is a modified literature procedure which is based on earlier work by lberl et al. with precise temperature control throughout the reaction [22,23]. Lcysteine hydrochloride monohydrate $(20 \mathrm{~g}, 0.11$ mol) was dissolved in $20 \mathrm{~mL}$ of water and stirred in an ice bath; then, $20 \mathrm{~mL}$ of an aqueous solution of sodium hydroxide $(16 \mathrm{~g}, 0.4 \mathrm{~mol})$ was added drop wise. Next allyl bromide $(10.8 \mathrm{~mL}$, $0.12 \mathrm{~mol}$ ) was gradually added to the solution and the reaction mixture was stirred for 14 hours at room temperature, cooled in an ice bath, and glacial acetic acid was slowly added to neutralize the reaction solution to $\mathrm{pH} 5$. The solution was filtered and the precipitate was washed three times with absolute ethanol. The white solid was crystalized using water to produce purified compound 3 . This was done by dissolving the crude L-deoxyalliin in a minimum volume of warm $60^{\circ} \mathrm{C}$ water. After complete dissolution, the solution was cooled to room temperature and was kept at $4^{\circ} \mathrm{C}$ overnight. The L-deoxyalliin crystals were separated, washed with cold ethanol and then dried under vacuum. The yield was $76 \%(14.2 \mathrm{~g})$ with purity of higher than $97 \%$. The characterization data of the product were consistent with the literature results [22,24-26]. TLC: $R_{f}$ 0.68; $[\alpha]^{25}{ }_{\mathrm{D}}=-10.4^{\circ}\left(c=1, \mathrm{H}_{2} \mathrm{O}\right)$; HRMS: (ESI, $\left.\mathrm{MH}^{+}\right)$calcd for $\mathrm{C}_{6} \mathrm{H}_{11} \mathrm{NO}_{2} \mathrm{~S}$, 162.0589, found 162.0584; ${ }^{1} \mathrm{H}$ NMR $(900 \mathrm{MHz}$, $\left.\mathrm{D}_{2} \mathrm{O}\right): \delta=2.97(\mathrm{dd}, \mathrm{J}=7.6,14.9 \mathrm{~Hz}, 1 \mathrm{H}$, $=\mathrm{CHCH}_{2} \mathrm{SCH}_{2}$ ), $3.07(\mathrm{dd}, \mathrm{J}=4.2,14.9 \mathrm{~Hz}, 1 \mathrm{H}$, $\left.=\mathrm{CHCH}_{2} \mathrm{SC}_{2}\right), 3.22(\mathrm{dd}, \mathrm{J}=7.3,13.8 \mathrm{~Hz}, 1 \mathrm{H}$, $\left.=\mathrm{CHCH}_{2} \mathrm{~S}\right), 3.24(\mathrm{dd}, \mathrm{J}=7.1,13.8 \mathrm{~Hz}, 1 \mathrm{H}$, $=\mathrm{CHCH}_{2} \mathrm{~S}$ ), 3.91 (dd, $\mathrm{J}=4.3,7.7 \mathrm{~Hz}, 1 \mathrm{H}$, $\mathrm{SCH}_{2} \mathrm{CHN}$ ), 5.21 (ddd, $1 \mathrm{H}, \mathrm{J}=1.3,2.2,9.9 \mathrm{~Hz}$, $\mathrm{CH}_{2}=\mathrm{CH}$ ), 5.23 (ddd, $1 \mathrm{H}, \mathrm{J}=1.3,2.8,17.1 \mathrm{~Hz}$, $\mathrm{C}_{2}=\mathrm{CH}$ ), 5.84 (dddd, $1 \mathrm{H}, \mathrm{J}=7.1,7.3,9.9,17.1$ 
$\mathrm{Hz}, \mathrm{CH} 2=\mathrm{CH}-\mathrm{S}$ ); ${ }^{13} \mathrm{C}$ NMR (DEPTQ, $225 \mathrm{MHz}$, $\left.\mathrm{D}_{2} \mathrm{O}\right): \delta=30.05\left(1 \mathrm{C}, \mathrm{S} \underline{\mathrm{C}} \mathrm{H}_{2} \mathrm{CHN}\right), 33.30(1 \mathrm{C}$, $\left.=\mathrm{CH}^{\mathrm{C}} \mathrm{H}_{2} \mathrm{~S}\right), 52.88\left(1 \mathrm{C}, \overline{\mathrm{CH}}_{2}=\underline{\mathrm{CH}}\right), 117.81(1 \mathrm{C}$, $\left.\mathrm{CH}_{2}=\mathrm{CH}\right), 132.91\left(1 \mathrm{C}, \mathrm{SCH}_{2} \underline{\mathrm{CHN}}\right), 172.32(1 \mathrm{C}$, $\mathrm{O} \underline{\mathrm{C}}=\mathrm{O}$ ).

\subsection{Synthesis of (2R)-2-Amino-3-[(S)- Prop-2-Enylsulfinyl] Propanoic acid (4) [(+)-L-Alliin]}

S-2-propenyl-L-cysteine sulfoxides were prepared by oxidation of the corresponding S-2propenyl-L-cysteines with hydrogen peroxide with quantitative yield following a procedure described previously which was based on earlier work by Yu et al. $[22,27]$ with modifications. To a $200 \mathrm{~mL}$ aqueous solution of compound $3(7.67 \mathrm{~g}$, $0.047 \mathrm{~mol})$ at $0^{\circ} \mathrm{C}, 5.4 \mathrm{~mL}$ of $30 \% \mathrm{H}_{2} \mathrm{O}_{2}(0.047$ mol) was added drop wise. The mixture was stirred at $20^{\circ} \mathrm{C}$ for $14 \mathrm{~h}$ and lyophilized. The crude diastereo mixture was determined to be 42 $\%$ (+)-L-alliin by NMR. A cascade fractional crystallization was used to produce diastereomericaly pure alliins. Crystallization was done using warm aqueous ethanol. This was achieved by adding minimum amount of $50^{\circ} \mathrm{C}$ water to dissolve alliin, followed by addition of ethanol until solution turned slight turbid. The mixture was then heated to yield a clear solution. This solution was kept overnight at $4^{\circ} \mathrm{C}$ to complete the crystallization. The crystals and the supernatant were separated and analyzed by NMR. Each crystallization supernatant contained more (-)-L-alliin while crystals were enriched in $(+)$-L-alliin. The crystals were subjected to fractional crystallization multiple times to isolate (+)-L-alliin (4) (1.0g, 13\% yield, > 97\% pure). The characterization data of the product were in accordance with published data $[23,26,28,29]$. TLC: $R_{f}$ 0.48; $[\alpha]^{25}=59^{\circ}\left(c=1, \mathrm{H}_{2} \mathrm{O}\right)$; HRMS: (ESI, $\mathrm{MH}^{+}$) calcd for $\mathrm{C}_{6} \mathrm{H}_{11} \mathrm{NO}_{3} \mathrm{~S}, 178.0532$, found: 178.0534; ${ }^{1} \mathrm{H}$ NMR $\left(900 \mathrm{MHz}, \mathrm{D}_{2} \mathrm{O}\right): \delta=$ $3.13\left(\mathrm{dd}, \mathrm{J}=7.7,14.0 \mathrm{~Hz}, 1 \mathrm{H},=\mathrm{CHCH}_{2} \mathrm{SOCH}_{2}\right.$ ), $3.34\left(\mathrm{dd}, \mathrm{J}=6.2,14.0 \mathrm{~Hz}, 1 \mathrm{H},=\mathrm{CHCH}_{2} \mathrm{SOCH}_{2}\right.$ ), $3.55\left(\mathrm{dd}, \mathrm{J}=8.1,13.3 \mathrm{~Hz}, 1 \mathrm{H},=\mathrm{CHCH}_{2} \mathrm{SO}\right)$, $3.75\left(\mathrm{dd}, \mathrm{J}=7.0,13.3 \mathrm{~Hz}, 1 \mathrm{H},=\mathrm{CHCH}_{2} \mathrm{SO}\right.$ ), 4.11 (dd, J = 6.2, 7.7 Hz, $1 \mathrm{H}, \mathrm{SOCH}_{2} \mathrm{C} \underline{\mathrm{HN}}$ ), 5.39 (d, $\left.1 \mathrm{H}, \mathrm{J}=17.2 \mathrm{~Hz}, \mathrm{CH}_{2}=\mathrm{CH}\right), 5.46(\mathrm{~d}, 1 \mathrm{H}, \mathrm{J}=$ $10.2 \mathrm{~Hz}, \mathrm{CH}_{2}=\mathrm{CH}$ ), 5.82 (dddd, $1 \mathrm{H}, \mathrm{J}=7.0,8.1$, 10.2, $17.2 \mathrm{~Hz}, \mathrm{CH} 2=\mathrm{CH}-\mathrm{SO}) ;{ }^{13} \mathrm{C}$ NMR (DEPTQ, $\left.225 \mathrm{MHz}, \mathrm{D}_{2} \mathrm{O}\right): \delta=51.59\left(1 \mathrm{C}, \mathrm{SO} \underline{\mathrm{C}} \mathrm{H}_{2} \mathrm{CHN}\right.$ ), $52.73\left(1 \mathrm{C}, \mathrm{SOCH}_{2} \underline{\mathrm{C}} \mathrm{HN}\right), \quad 57.08$ (1 C, $\left.=\mathrm{CH}_{\mathrm{C}} \mathrm{H}_{2} \mathrm{SO}\right), 126.31\left(1 \mathrm{C}, \mathrm{CH}_{2}=\underline{\mathrm{C}} \mathrm{H}\right), 127.33$ (1 C, $\left.\mathrm{CH}_{2}=\mathrm{CH}\right), 173.34(1 \mathrm{C}, \mathrm{O} \underline{\mathrm{C}}=\mathrm{O})$. In addition, 2D ${ }^{1} \mathrm{H},{ }^{1} \mathrm{H}$ correlation spectrometry (COSY) has confirmed the ${ }^{1} \mathrm{H}$ NMR assignments and 2- ${ }^{1} \mathrm{H}$, ${ }^{13} \mathrm{C}$ heteronuclear multiple quantum coherence
(HMQC) spectrum, which contains a peak for each unique proton attached to the carbon being considered, has confirmed the ${ }^{13} \mathrm{C}$ NMR assignments $(\delta 51.59$ and $\delta 57.08$ have been wrongfully assigned to $=\mathrm{CH}_{\mathrm{CH}} \mathrm{SO}$ and $\mathrm{SO} \mathrm{CH}_{2} \mathrm{CHN}$ in previous publication [29]).

\subsection{Synthesis of (2R)-2-Amino-3-[(R)- Prop-2-Enylsulfinyl] Propanoic Acid (5) [(-)-L-Alliin]}

Compound $\mathbf{5}$ was synthesized using the same procedure as for the synthesis of compound 4 . After completion, the supernatant was subject to fractional crystallization in warm aqueous ethanol and the process was repeated a number of times to produce pure compound $5(0.9 \mathrm{~g}, 12 \%$ yield, $>95 \%$ pure). The characterization data of the product were consistent with the literature results $[23,26,28,29]$. TLC: $R_{f} 0.48 ;[\alpha]^{25}{ }_{\mathrm{D}}=-61^{\circ}(c=1$, $\left.\mathrm{H}_{2} \mathrm{O}\right)$; HRMS (ESI, $\left.\mathrm{MH}^{+}\right): \mathrm{m} / \mathrm{z}$ calcd for $\mathrm{C}_{6} \mathrm{H}_{11} \mathrm{NO}_{3} \mathrm{~S}$ : 178.0532 ; found: $178.0534 ;{ }^{1} \mathrm{H}$ NMR $\left(900 \mathrm{MHz}, \mathrm{D}_{2} \mathrm{O}\right): \delta=3.28(\mathrm{dd}, \mathrm{J}=8.5,14.5 \mathrm{~Hz}, 1$ $\left.\mathrm{H},=\mathrm{CHCH}_{2} \mathrm{SOC}_{2}\right), 3.32(\mathrm{dd}, \mathrm{J}=3.3,14.5 \mathrm{~Hz}, 1$ $\left.\mathrm{H},=\mathrm{CHCH}_{2} \mathrm{SOCH}_{2}\right), 3.59(\mathrm{dd}, \mathrm{J}=7.9,13.3 \mathrm{~Hz}, 1$ $\left.\mathrm{H},=\mathrm{CHCH}_{2} \mathrm{SO}\right), 3.74$ (dd, J = 7.1, $13.3 \mathrm{~Hz}, 1 \mathrm{H}$, $\left.=\mathrm{CHCH}_{2} \mathrm{SO}\right), 4.15(\mathrm{dd}, \mathrm{J}=3.3,8.5 \mathrm{~Hz}, 1 \mathrm{H}$, $\left.\mathrm{SOCH}_{2} \mathrm{CHN}\right), \quad 5.41(\mathrm{~d}, 1 \mathrm{H}, \quad \mathrm{J}=17.2 \mathrm{~Hz}$, $\left.\mathrm{CH}_{2}=\mathrm{CH}\right), 5.46\left(\mathrm{~d}, 1 \mathrm{H}, \mathrm{J}=10.2 \mathrm{~Hz}, \mathrm{CH}_{2}=\mathrm{CH}\right)$, 5.82 (dddd, $1 \mathrm{H}, \mathrm{J}=7.1,7.9,10.2,17.2 \mathrm{~Hz}$, $\mathrm{CH} 2=\mathrm{C} \underline{\mathrm{H}}-\mathrm{SO}$ ); ${ }^{13} \mathrm{C}$ NMR (DEPTQ, $225 \mathrm{MHz}$, $\left.\mathrm{D}_{2} \mathrm{O}\right): \delta=51.34\left(1 \mathrm{C}, \mathrm{SO} \underline{\mathrm{CH}} \mathrm{H}_{2} \mathrm{CHN}\right), 52.10$ (1 C, $\mathrm{SOCH}_{2} \underline{\mathrm{CHN}}$ ), 56.55 (1 C, $\left.=\mathrm{CHCH}_{2} \mathrm{SO}\right), 126.24$ (1 C, $\mathrm{CH}_{2}=\underline{\mathrm{CH}}$ ), 127.40 (1 C, $\left.\underline{\mathrm{CH}}_{2}=\mathrm{CH}\right), 173.21$ (1 $\mathrm{C}, \mathrm{O} \underline{\mathrm{C}}=\mathrm{O}$ ). In addition, 2-D ${ }^{1} \mathrm{H},{ }^{1} \mathrm{H}$ COSY has confirmed the ${ }^{1} \mathrm{H}$ NMR assignments and 2-D ${ }^{1} \mathrm{H}$, ${ }^{13} \mathrm{C} \mathrm{HMQC}$ spectrum has confirmed the ${ }^{13} \mathrm{C}$ NMR assignments.

\subsection{Synthesis of Fmoc-(2R)-2-Amino-3- [(S)-Prop-2-Enylsulfinyl] Propanoic Acid (6) ([Fmoc-(+)-Alliin])}

Compound 6 was synthesized following a procedure with modifications [30-33]. Alliin (3.3 $\mathrm{mg}, 1$ equiv) was dissolved in $660 \mu \mathrm{L}$ of water and $\mathrm{NaHCO}_{3}$ (6.2 mg, 4 equiv), $\mathrm{Na}_{2} \mathrm{CO}_{3}$ (3.9 mg, 2 equiv), and $50 \mu \mathrm{L}$ of 1,4-dioxane was added in sequence. Subsequently, N-(9fluorenylmethoxycarbonyloxy) succinimide (Fmoc-OSu) was added drop wise to this clear alliin solution, which became turbid at first but cleared after stirring overnight. Fmoc-OSu solution was prepared by dissolving Fmoc-OSu powder (7.5 mg, 1.2 equiv) in $165 \mu \mathrm{L}$ of 1,4dioxane. Fmoc-alliin was purified by RP-C18 HPLC and dried as a white powder $(6.7 \mathrm{mg}, 90$ 
$\%$ yield). The purity of the product was higher than $97 \%$ determined by NMR. The characterization data of the product were as follows. TLC: $R_{f}$ 0.75; $\operatorname{HRMS}\left(\mathrm{ESI}, \mathrm{MH}^{+}\right): \mathrm{m} / \mathrm{z}$ calcd for $\mathrm{C}_{21} \mathrm{H}_{21} \mathrm{NO}_{5} \mathrm{~S}$ : 400.1213; found: 400.1210; RP-HPLC ( $\left.t_{R}, \min \right): 18 ;{ }^{1} \mathrm{H}$ NMR (900 $\mathrm{MHz}, \mathrm{CD}_{3} \mathrm{CN}$ ): $\delta=3.55$ (dd, J = 7.2, $13.7 \mathrm{~Hz}, 1$ $\left.\mathrm{H},=\mathrm{CHCH}_{2} \mathrm{SOCH}_{2}\right), 3.81(\mathrm{dd}, \mathrm{J}=5.8,13.7 \mathrm{~Hz}, 1$ $\left.\mathrm{H},=\mathrm{CHCH}_{2} \mathrm{SOCH}_{2}\right), 3.93(\mathrm{dd}, \mathrm{J}=7.8,13.2 \mathrm{~Hz}, 1$ $\left.\mathrm{H},=\mathrm{CHCH}_{2} \mathrm{SO}\right), 4.08(\mathrm{dd}, \mathrm{J}=7.1,13.2 \mathrm{~Hz}, 1 \mathrm{H}$, $\left.=\mathrm{CHCH}_{2} \mathrm{SO}\right), 4.67$ (dd, $\mathrm{J}=6.7,7.0 \mathrm{~Hz}, 1 \mathrm{H}$, $\mathrm{SOCH}_{2} \mathrm{CHN}$ ), 4.79 (dd, J = 6.5, 16.3 Hz, $1 \mathrm{H}$, $\mathrm{CHCH}_{2} \mathrm{OCONH}$ ), 4.81 (dd, J = 7.0, $16.3 \mathrm{~Hz}, 1 \mathrm{H}$, $\mathrm{CHCH}_{2} \mathrm{OCONH}$ ), 4.97 (dd, J = 6.5, $7.0 \mathrm{~Hz}, 1 \mathrm{H}$, $\left.\mathrm{CHCH}_{2} \mathrm{OCONH}\right), 5.83(\mathrm{~d}, 1 \mathrm{H}, \mathrm{J}=17.1 \mathrm{~Hz}$, $\left.\mathrm{CH}_{2}=\mathrm{CH}\right), 5.87\left(\mathrm{~d}, 1 \mathrm{H}, \mathrm{J}=10.0 \mathrm{~Hz}, \mathrm{CH}_{2}=\mathrm{CH}\right)$, 6.29 (dddd, $1 \mathrm{H}, \mathrm{J}=6.7,7.1,10.0,17.1,7.2 \mathrm{~Hz}$, $\mathrm{CH} 2=\mathrm{C} \underline{\mathrm{H}}-\mathrm{SO}$ ), 7.77 (dd, J = 7.2, 7.4 Hz, $2 \mathrm{H}$, $\left.\mathrm{CHCH}=\mathrm{C} C \mathrm{HCH}_{2} \mathrm{OCONH}\right), 7.85(\mathrm{dd}, \mathrm{J}=6.7,6.9$ $\left.\mathrm{Hz}, 2 \mathrm{H}, \quad \mathrm{CH}=\mathrm{CHCH}=\mathrm{CCHCH}_{2} \mathrm{OCONH}\right), 8.08$ (dd, J = 6.3, $6.7 \mathrm{~Hz}, 1 \mathrm{H}, \mathrm{C}$ $8.25 \quad\left(\mathrm{dd}, \quad \mathrm{J}=6.0,7.2 \quad \mathrm{~Hz}_{13}{ }^{1} \mathrm{H}\right.$, (DEPTQ, $225 \mathrm{MHz}, \mathrm{D}_{2} \mathrm{O}$ ): $\delta=47.27$ (1 C,

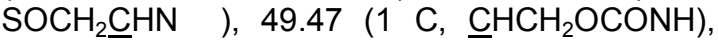
51.98 (1 C, $\mathrm{SO}_{\mathrm{CH}} \mathrm{CHN}$ ), 55.06 (1 C, $\left.=\mathrm{CHCH}_{2} \mathrm{SO}\right), \quad 67.26$ (1 C, $\left.\mathrm{CHCH}_{2} \mathrm{OCONH}\right)$, $120.52\left(1 \mathrm{C}, \quad=\underline{\mathrm{CHCH}_{2} \mathrm{SO}}\right), 124.78$ (1 C, $\left.\mathrm{CH}_{2}=\mathrm{CH}\right), \quad 125.79 \quad(2) \quad \mathrm{C}$, $\underline{\mathrm{C}} \mathrm{HCH}=\mathrm{CHCH}=\mathrm{CCHCH}_{2} \mathrm{OCONH}$ ), 125.67 (2 C, $\underline{\mathrm{C}} \mathrm{H}=\mathrm{CCHCH}_{2} \mathrm{OCONH}$ ), 127.80 (2 C, $\left.\underline{\mathrm{C}} \mathrm{HCH}=\mathrm{CCHCH}_{2} \mathrm{OCONH}\right), \quad 128.37$ (2 C, $\underline{\mathrm{C}} \mathrm{H}=\mathrm{CHCH}=\mathrm{CCHCH}_{2} \mathrm{OCONH}$ ), 141.50 (2 C, $\left.\underline{\mathrm{C}} \mathrm{H}=\mathrm{CHCH}=\mathrm{CHCH}=\mathrm{CCHCH}{ }_{2} \mathrm{OCONH}\right), 144.28(2$ $\left.\mathrm{C}, \quad \mathrm{CH}=\mathrm{CCHCH}_{2} \mathrm{OCONH}\right), 157.02(1 \mathrm{C}$,

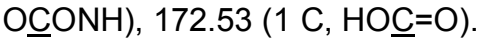

\subsection{Synthesis of Methyl (2R)-2-Amino-3- [(S)-Prop-2-Enylsulfinyl] Propanoate (7) ([(+)-L-Alliin Methyl Ester]) and Methyl (2S)-2-Amino-3-[(S)-Prop-2- Enylsulfinyl] Propanoate (8) ([(+)-D- Alliin Methyl Ester])}

Compound $\mathbf{7}$ and 8 were synthesized as a mixture following a procedure described with modifications [34,35]. Five $\mathrm{mg}$ of alliin was dissolved in $1.2 \mathrm{M} \mathrm{HCl}$ in anhydrous methanol $(700 \mu \mathrm{L})$ and mixed overnight. Seventy $\mathrm{mg}$ of $\mathrm{NH}_{4} \mathrm{HCO}_{3}$ was slowly added to neutralize the solution and the solution was lyophilized. The white powder containing $59 \%$ of $(+)$-L-alliin and $41 \%(+)$-D-alliin methyl ester was dissolved in aqueous $50 \%$ acetonitrile and HPLC was used to isolate the (+)-DL-alliin methyl ester. Alliin methyl ester was eluted at $4.6 \mathrm{~min}$ and dried as a white powder with $91 \%$ yield. The purity of the product was higher than $97 \%$ determined by NMR. The characterization data of the product were as follows. TLC: $R_{f}$ 0.46; HRMS $\left(\mathrm{ESI}, \mathrm{MH}^{+}\right): \mathrm{m} / \mathrm{z}$ calcd for $\mathrm{C}_{7} \mathrm{H}_{13} \mathrm{NO}_{3} \mathrm{~S}$ : 192.0689; found: 192.0682; RP-HPLC $\left(t_{R}, \mathrm{~min}\right): 4.7 ;{ }^{1} \mathrm{H}$ NMR (900 $\left.\mathrm{MHz}, \mathrm{D}_{2} \mathrm{O}\right): \delta[(+)$-L-alliin methyl ester $]=3.33$ (dd, J = 5.9, $14.1 \mathrm{~Hz}, 1 \mathrm{H},=\mathrm{CHCH}_{2} \mathrm{SOCH}_{2}$ ), 3.42 (dd, J = 6.4, $14.1 \mathrm{~Hz}, 1 \mathrm{H},=\mathrm{CHCH}_{2} \mathrm{SOCH}_{2}$ ), 3.57 (dd, J = 8.0, $13.3 \mathrm{~Hz}, 1 \mathrm{H},=\mathrm{CHCH}_{2} \mathrm{SO}$ ), 3.75 (dd, $\left.\mathrm{J}=8.2,13.3 \mathrm{~Hz}, 1 \mathrm{H},=\mathrm{CHCH}_{2} \mathrm{SO}\right), 3.77(\mathrm{~s}, 3 \mathrm{H}$, $\left.\mathrm{COOC}_{3}\right), 4.61(\mathrm{dd}, \mathrm{J}=6.2,6.2 \mathrm{~Hz}, 1 \mathrm{H}$, $\left.\mathrm{SOCH}_{2} \mathrm{C} \underline{\mathrm{H} N}\right), \quad 5.40(\mathrm{~d}, 1 \mathrm{H}, \mathrm{J}=17.2 \mathrm{~Hz}$, $\left.\mathrm{CH}_{2}=\mathrm{CH}\right), 5.47\left(\mathrm{~d}, 1 \mathrm{H}, \mathrm{J}=10.1 \mathrm{~Hz}, \mathrm{CH}_{2}=\mathrm{CH}\right)$, 5.82 (dddd, $1 \mathrm{H}, \mathrm{J}=8.0,8.2,10.1,17.2 \mathrm{~Hz}$, $\mathrm{CH} 2=\mathrm{C}$ - $-\mathrm{SO}$ ); ${ }^{13} \mathrm{C}$ NMR (DEPTQ, $225 \mathrm{MHz}$, $\left.\mathrm{D}_{2} \mathrm{O}\right): \delta=50.74\left(1 \mathrm{C}, \mathrm{SO} \mathrm{CH}_{2} \mathrm{CHN}\right), 50.80(1 \mathrm{C}$, $\mathrm{SOCH}_{2} \underline{\mathrm{CHN}}$ ), $55.96\left(1 \mathrm{C}, \mathrm{COO}^{\mathrm{C}} \mathrm{H}_{3}\right), 57.02$ (1 $\left.\mathrm{C},=\mathrm{CH}_{\mathrm{C}} \mathrm{H}_{2} \mathrm{SO}\right), 125.96\left(1 \mathrm{C}, \mathrm{CH}_{2}=\underline{\mathrm{C}} \mathrm{H}\right), 127.63$ $\left(1 \mathrm{C}, \underline{\mathrm{C}} \mathrm{H}_{2}=\mathrm{CH}\right), 170.26(1 \mathrm{C}, \mathrm{O} \underline{\mathrm{C}}=\mathrm{O})$.

${ }^{1} \mathrm{H}$ NMR $\left(900 \mathrm{MHz}, \mathrm{D}_{2} \mathrm{O}\right): \delta[(+)$-D-alliin methyl ester] $=3.36(\mathrm{dd}, \mathrm{J}=8.3,14.6 \mathrm{~Hz}, 1 \mathrm{H}$, $=\mathrm{CHCH}_{2} \mathrm{SOCH}_{2}$ ), $3.40(\mathrm{dd}, \mathrm{J}=4.1,14.6 \mathrm{~Hz}, 1 \mathrm{H}$, $\left.=\mathrm{CHCH}_{2} \mathrm{SOCH}_{2}\right), 3.60(\mathrm{dd}, \mathrm{J}=7.8,13.4 \mathrm{~Hz}, 1 \mathrm{H}$, $\left.=\mathrm{CHCH}_{2} \mathrm{SO}\right), 3.76(\mathrm{dd}, \mathrm{J}=8.0,13.3 \mathrm{~Hz}, 1 \mathrm{H}$, $\left.=\mathrm{CHCH}_{2} \mathrm{SO}\right), 3.79\left(\mathrm{~s}, 3 \mathrm{H}, \mathrm{COOC} \mathrm{H}_{3}\right), 4.58(\mathrm{dd}, \mathrm{J}$ $\left.=4.2,8.3 \mathrm{~Hz}, 1 \mathrm{H}, \mathrm{SOCH}_{2} \mathrm{CHN}\right), 5.41(\mathrm{~d}, 1 \mathrm{H}, \mathrm{J}=$ $\left.17.2 \mathrm{~Hz}, \mathrm{CH}_{2}=\mathrm{CH}\right), 5.47(\mathrm{~d}, 1 \mathrm{H}, \mathrm{J}=10.1 \mathrm{~Hz}$, $\mathrm{CH}_{2}=\mathrm{CH}$ ), 5.82 (dddd, $1 \mathrm{H}, \mathrm{J}=7.8,8.0,10.1$, $17.2 \mathrm{~Hz}, \mathrm{CH} 2=\mathrm{CH}-\mathrm{SO}$ ); ${ }^{13} \mathrm{C}$ NMR (DEPTQ, 225 $\mathrm{MHz}, \mathrm{D}_{2} \mathrm{O}$ ): $\delta=50.30\left(1 \mathrm{C}, \mathrm{SOCH}_{2} \mathrm{CHN}\right), 50.44$ $\left(1 \mathrm{C}, \mathrm{SO} \mathrm{CH}_{2} \mathrm{CHN}\right), 56.14\left(1 \mathrm{C}, \mathrm{COO} \mathrm{CH}_{3}\right), 56.69$ (1 $\left.\mathrm{C},=\mathrm{CH}_{2} \mathrm{H}_{2} \mathrm{SO}\right), 125.96\left(1 \mathrm{C}, \mathrm{CH}_{2}=\underline{\mathrm{C}} \mathrm{H}\right)$, $127.66\left(1 \mathrm{C}, \underline{\mathrm{C}} \mathrm{H}_{2}=\mathrm{CH}\right), 170.45(1 \mathrm{C}, \mathrm{O} \underline{\mathrm{C}}=\mathrm{O})$.

\subsection{MTT Cell Viability Assay of in situ Allicin}

The viability of the Mus musculus colon carcinoma CT26.WT cells after treatment with in situ allicin was evaluated by 3-(4,5Dimethylthiazol-2-yl)-2, 5-diphenyltetrazolium bromide (MTT) cell viability assay (Wallert and Provost Laboratory, Minnesota State University, Moorhead, MN) following a procedure described previously with modifications [8]. This assay is based on the conversion of MTT to MTTformazon by mitochondrial enzymes. MTT assay was performed as follows: first, cells were plated at a density of 7,500 cells/well $(144 \mu \mathrm{L} /$ well $)$ in 96-well plates and incubated at $37^{\circ} \mathrm{C}$ in a humid environment containing $5 \% \mathrm{CO}_{2}$ overnight. Then, $8 \mu \mathrm{L}$ of alliin at varying concentrations was added to each well. After 1-7 days of incubation, $8 \mu \mathrm{L}$ of alliinase at varying concentrations was mixed into each well. The following day, $30 \mu \mathrm{L}$ of MTT solution ( $5 \mathrm{mg} / \mathrm{mL}$ in PBS) was added to 
each well. After incubation for $3.5 \mathrm{~h}$, the medium was aspirated and $150 \mu \mathrm{L}$ of MTT solvent $(4 \mathrm{mM}$ $\mathrm{HCl}$ and $0.1 \% \mathrm{NP}-40$ in isopropanol) was added to each well. After mixing well on an orbital shaker for $20 \mathrm{~min}$, absorbance of the maximum at $545 \mathrm{~nm}$ with a reference filter of $630 \mathrm{~nm}$ was read by a multimode microplate reader SpectraMax M2 (Molecular Devices, Sunnyvale, $\mathrm{CA})$. The absorbance readings revealed the percentage of the cell viability. The half maximal inhibitory concentration $\left(\mathrm{IC}_{50}\right)$ was calculated using a four-parameter logistic curve of SigmaPlot (Systat Software, Richmond, VA, USA). A control group (PBS, alliin, or alliinase treated cells) or blank group (water) was also included and the absorbance was considered to be $100 \%$ cell viability. Experiments were performed in triplicates. Data are presented as means \pm standard deviations. Where appropriate, one-way analysis of variance (ANOVA) or student's paired t test was performed using SigmaPlot. $P$ values less than 0.05 were considered as statistically significant. The CT26.WT cell line was used because it can be easily inoculated into BALB/c mice for later in vivo studies and there were reports that garlic consumption is beneficial for the suppression of colon cancer.

\subsection{Antimicrobial Activity of in situ Allicin}

A bacterial plate-diffusion growth inhibition assay was used to assess the efficacy of in situ allicin on eliminating human pathogens [36-39]. Grampositive Staphylococcus aureus subsp. aureus Rosenbach (ATCC ${ }^{\circledR} 6538^{\mathrm{TM}}$ ) and gram-negative Escherichia coli (Migula) Castellani and Chalmers (ATCC ${ }^{\circledR} 8739^{\mathrm{TM}}$ ) were used as test microorganisms. Bacteria in log phase growth in LB medium (Difco laboratories, Detroit, MI, USA) were grown at $37^{\circ} \mathrm{C}$ oven to an $\mathrm{OD}_{560}=0.18$ and diluted 10 times with LB medium. $0.5 \mathrm{~mL}$ of the bacterium solution was spread on a $10 \mathrm{~cm}$ diameter petri dish with agar, which was prepared with $15 \mathrm{~mL}$ of a sterilized LB agar aqueous solution (40 g/liter). Ten $\mathrm{mm}$ diameter holes (wells) were punched out and filled with $100 \mu \mathrm{L}$ PBS solution containing $20 \mu \mathrm{L}$ of various concentrations of alliin, alliinase, allicin, AGE, a mixture of alliin and alliinase, or PBS. Plates were then incubated overnight at $37^{\circ} \mathrm{C}$ and the diameter of the inhibition zone was measured. A dilution series of the in situ allicin was used to establish the proportionality of the relationship between the amount of active allicin and diameter of inhibition zone.

\subsection{Flow Cytometric Analysis of Cell Cycle Using Propidium lodide DNA Staining}

Mus musculus colon carcinoma CT26.WT cells were plated at a density of $1 \times 10^{5}$ cells/well in 6well plates, permitted to adhere and grown for 48 $\mathrm{h}$ in RPMI-1640 with 10\% FBS. Wells were treated separately with $100 \mu \mathrm{L}$ PBS solution containing $20 \mu \mathrm{L}$ of alliin, alliinase, allicin, AGE, a mixture of alliin and alliinase, or PBS at a range of concentrations for $12 \mathrm{~h}$. The cells $\left(\sim 3.6 \times 10^{5}\right)$ were then harvested by trypsin-EDTA treatment into sterilized $15 \mathrm{~mL}$ of Falcon tubes. After washing twice with $2 \mathrm{~mL}$ PBS, centrifuging at 300 $x \mathrm{~g}$ for 5 minutes, and decanting the buffer from the pelleted cells, cells were fixed in $70 \%$ cold ethanol at $4^{\circ} \mathrm{C}$ overnight. The $70 \%$ cold ethanol was added drop wise to the pellet while vortexing to ensure fixation of all cells and minimize clumping. Before analysis, cells were washed twice with PBS, suspended in $500 \mu \mathrm{L}$ of PBS containing $0.5 \%$ BSA, and treated with 200 $\mu \mathrm{g} / \mathrm{mL}$ RNase A (Roche Diagnostics, Indianapolis, IN) and $40 \mu \mathrm{g} / \mathrm{mL}$ propidium iodide (PI; Sigma Corp., St. Louis, MO). Propidium iodide binds to double stranded DNA by intercalating between base pairs. After incubation for $30 \mathrm{~min}$ at $37^{\circ} \mathrm{C}$ and single cell suspension with Falcon cell-strainer (Corning Inc., Durham, NC, USA), the cells were subjected to DNA content analysis. The PI fluorescence was analyzed by using a Cyan ADP flow cytometer with $488 \mathrm{~nm}$ line of argon-ion laser excitation (Beckman Coulter, Pasadena, CA). Flow cytometer was cleaned with bleach once and with water twice before it was used. In all the experiments, cells were gated on forward and side scatter to eliminate dead cells and debris. Data from at least 10,000 cells were analyzed with Summit software (Beckman Coulter, Pasadena, CA). Each DNA histogram was analyzed for peak position and for the percentage of cells in different histogram regions. Cell cycle distributions were obtained by deconvolution of histograms using Peakfit software (Systat Software, Richmond, VA, USA). This technique measures DNA content of 5,000 cells per second and trace the dynamic changes in cell proliferation cycle. Data show percentages of cell in different phases like sub- $G_{1}, G_{1}, S$, and $\mathrm{G}_{2} / \mathrm{M}[40]$.

\section{RESULTS AND DISCUSSION}

Aqueous garlic extract (AGE) was prepared from garlic clove according to with modification in 
hepes buffer (50 mM, pH 7.2) containing $10 \%$ glycerol, $1 \mathrm{mM} \mathrm{CaCl} 2,1 \mathrm{mM} \mathrm{MnCl} 2,1 \mathrm{mM}$ $\mathrm{MgCl} 2,20 \mu \mathrm{M}$ pyridoxal 5'-phosphate (PLP), and $0.25 \mathrm{M} \mathrm{NaCl}$ at a concentration of $1 \mathrm{~g} / \mathrm{mL}[8,9]$. Glycosylated dimeric alliinase, which is used to convert bioinactive alliin to bioactive allicin, is purified to homogeneity from AGE. Alliinase is the major protein in $\mathrm{AGE}$, and $\mathrm{NaCl}$ is required to preserve the enzymatic activity of alliinase because it can stabilize the alliinase dimer [41]. The inclusion of PLP and glycerol in hepes buffers is necessary to stabilize the enzyme during purification $[42,43]$. Our results from cancer cell viability assay MTT assay, bacterial plate-diffusion growth inhibition assay, and flow cytometry cell cycle analysis confirm the importance of buffer on the activity of alliinase (data not shown). Alliinase is completely inactive if prepared in water, semi-active if prepared in PBS, and most active if prepared in the hepes buffer. However, there is no detrimental effect if AGE is prepared in water because garlic itself contains the necessary compounds to stabilize the alliinase. It is the subsequent purification steps which require the hepes buffer.

Many protocols have been used to prepare alliinase from AGE using gel-filtration, ionexchange, hydroxyapatite, and/or ConASepharose 4B affinity columns with varying enzymatic activities and protein purities obtained at low yield [41,44-46]. Reports on recombinant expression of alliinase are scarce [47-49]. Here
PD10 and high-resolution gel-filtration columns were used to produce highly purified alliinase with high yield. Many different kinds of columns such as ion-exchange, hydroxyapatite, hydrophobic, and ConA-Sepharose columns do not perform well in this study. A PD10 column is used to separate high-molecular weight $(>5000$ $\mathrm{Da}$ ) biomolecules from low-molecular weight compounds. All purification steps are done at $4^{\circ} \mathrm{C}$ in this facile procedure. Analysis of samples in every steps of the alliinase preparation by gel electrophoresis is shown in Fig. 1. Data reveal that the AGE contains two major protein bands at 52 and $12 \mathrm{kDa}$ together with several minor bands. LC/MS/MS data on trypsin in-gel digestion of these two protein bands together with MassMatrix and $\mathrm{X}$ ! Tandem database searches have confirmed that the $52 \mathrm{kDa}$ protein is the enzyme alliinase, which is a mannose rich glycoprotein, and the $12 \mathrm{kDa}$ protein is lectin, which is specific for mannose (data not shown). This observation points to possible interaction between these two proteins [44]. Concentration of alliinase was determined to be $1.5 \mathrm{mg} / \mathrm{mL}$ by SDS-PAGE band intensity using BSA as standard. SDS-PAGE after purification on PD10 (Fig. 1, Lane A) shows a similar protein profile to AGE and purification on high-resolution gelfiltration (Fig. 1, Lane B) reveals that alliinase is the only protein stained with Coomassie blue. Eighty percent of the alliinase in AGE is recovered with this protocol.
A

$260 \mathrm{kDa}$

160

110

80

60

50

40

30

20

15

10

3.5
B

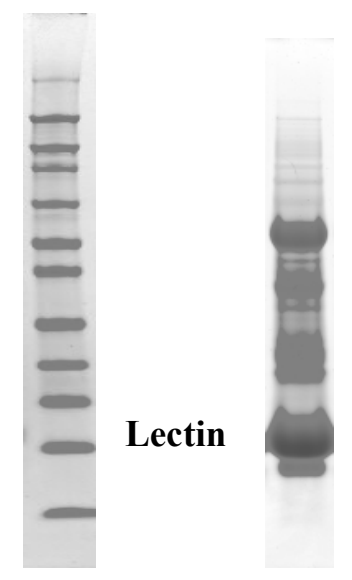

C

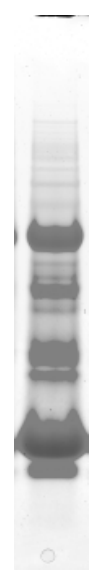

D

\section{Alliinase}

Lane A, protein molecular weight markers; Lane B, aqueous garlic extract (AGE); Lane $C$, protein fraction of PD10 purification of AGE;

Lane $D$, alliinase purified on high-resolution HPLC size exclusion chromatography

Fig. 1. SDS-PAGE analyses of protein samples 
The enzyme alliinase contains one PLP cofactor per subunit and belongs to the class I of PLPdependent enzymes. It is able to cleave the C-S bond of sulfoxide derivatives of cysteine to produce allicin. The enzyme activity assay of alliinase was determined by the spectrophotometric assay using 4mercaptopyridine (4-MP) method using pure (+)L-alliin in a cell free system according to Miron et al. with modifications [21]. One unit of enzyme activity was defined as releasing $1 \mu \mathrm{mol}$ pyruvate per minute. The final pure alliinase fraction prepared in this study shows an activity of 12 units/mg which is similar to the allinase purified in Miron et al. [21] and much higher than the allinase purified in Mallika et al. [46]. It is interesting to note that some of the partially purified allinase fractions containing lectin show higher enzyme activity than the pure allinase fraction (data not shown), suggesting that lectin might enhance the activity of allinase.

The course of the synthesis of (+)-L-alliin, (-)-Lalliin, Fmoc-(+)-alliin or (+)-DL-alliin methyl ester is illustrated in Schematic 1. The synthesis started with the formation of L-deoxyalliin (3) from the commercially available allyl bromide (1) and hydrochloride of L-cysteine (2) under alkaline conditions. A white precipitate was formed after the reaction solution was neutralized with acetic acid. Compound 3 was purified from the precipitate by crystalization in warm water and it does not show NMR signal for methyl group. It is interesting that proton coupling patterns of compound 3 between 2.97 and 3.07 and between 3.22 and 3.24 require non-firstorder correction just as in the case of deoxyisoalliin, isoalliin, or allicin $[8,9,22,50]$.

(+)-L-alliin (4) and (-)-L-alliin (5) were prepared by oxidation of the corresponding L-deoxyalliin (3) with hydrogen peroxide in $\mathrm{H}_{2} \mathrm{O}$. The reaction is very efficient with a high yield. By careful control of temperature and concentration, further oxidation to sulfate is avoided. This oxidation reaction converts the divalent sulfur of compounds 4 and 5 to trivalent sulfur, which becomes a chiral center. Because the oxygen can be introduced from either side of the sulfur, a mixture of separable diastereomers is produced.

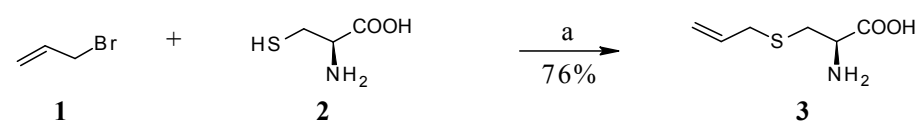

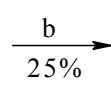

4

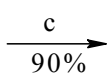

4

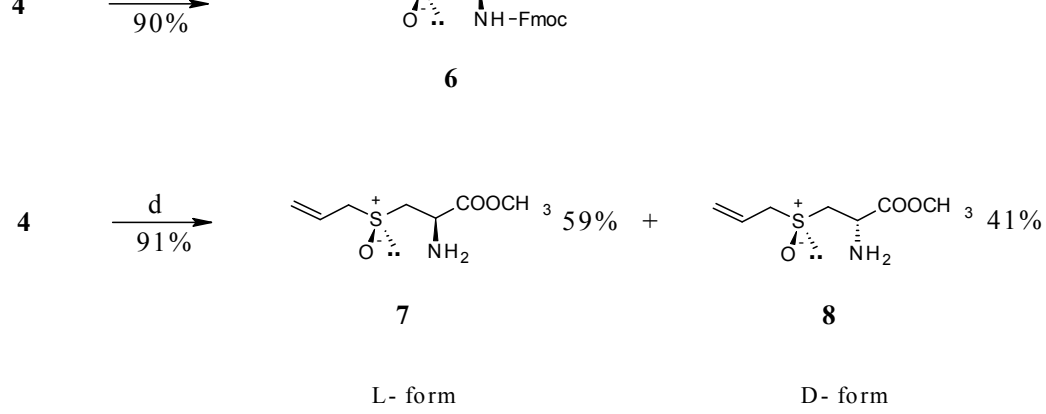

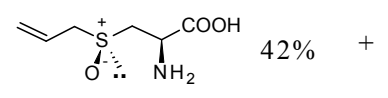

4

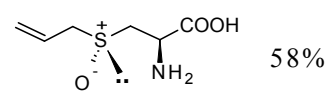

5

\footnotetext{
a) $\mathrm{NaOH}, \mathrm{H}_{2} \mathrm{O}, 20^{\circ} \mathrm{C}, 14 \mathrm{~h}, \mathrm{RP}-\mathrm{HPLC}$; b) $30 \% \mathrm{H}_{2} \mathrm{O}_{2}, \mathrm{H}_{2} \mathrm{O}, 20^{\circ} \mathrm{C}, 14 \mathrm{~h}$, repeated fractional crystallization;

c) $\mathrm{NaHCO}_{3}, \mathrm{Na}_{2} \mathrm{CO}_{3}, 1,4$ dioxane, Fmoc-OSu; d) $\mathrm{NaHCO}_{3}, \mathrm{Na}_{2} \mathrm{CO}_{3}$, 1,4-dioxane, Fmoc-OSu;

d) $\mathrm{HCl}$, anhydrous $\mathrm{MeOH}$, neutralize with $\mathrm{NH}_{4} \mathrm{HCO}_{3}$ and lyophilized
}

\section{Scheme 1. Chemical syntheses of (+)-L-alliin, (-)-L-alliin, (+)-Fmoc-L-alliin, and (+)-L,D-methyl alliin ester}


Although many papers have reported synthesis of compounds 4 and 5, these methods produce either low yield or low purity $[20,28,29]$. Solvent extractions and multiple fractional crystallization are used to separate and purify compounds 4 and 5 , which are dried as white powders with $13 \%$ and $12 \%$ total yield of $>97 \%$ purity, respectively. ${ }^{1} \mathrm{H},{ }^{13} \mathrm{C}$ NMR chemical shifts are quite similar between (+) and (-) isomers except for ${ }^{1} \mathrm{H}$ NMR chemical shift of $=\mathrm{CHCH}_{2} \mathrm{SOCH}_{2}$. 2D ${ }^{1} \mathrm{H},{ }^{1} \mathrm{H}$ correlation spectrometry (COSY) has confirmed the ${ }^{1} \mathrm{H}$ NMR assignments and 2- ${ }^{1} \mathrm{H}$, ${ }^{13} \mathrm{C}$ Heteronuclear Multiple Quantum Coherence (HMQC) spectrum, which contains a peak for each unique proton attached to the carbon being considered, has confirmed the ${ }^{13} \mathrm{C}$ NMR $(\delta 51.59$ and $\delta 57.08$ have been wrongfully assigned to $=\mathrm{CHC} \mathrm{H}_{2} \mathrm{SO}$ and $\mathrm{SOCH}_{2} \mathrm{CHN}$ for Compound 4 in previous publication ${ }^{29}$ ). The spin coupling pattern between $\delta 3.13$ and $\delta 3.34$ and between $\delta 3.54$ and $\delta 3.75$ of compound 4 can be understood by non-first-order pattern resulting from the ratio between the chemical shift difference in $\mathrm{Hz}$ and the spin coupling of $14.0(\Delta \vee / J=195.7 / 14.0)$ and $13.6(\Delta \vee / \mathrm{J}=182.7 / 13.4)$, respectively. The spin coupling pattern between $\delta 3.28$ and $\delta 3.32$ and between $\delta 3.59$ and $\delta 3.74$ of compound 5 can be understood by non-first-order pattern resulting from the ratio between the chemical shift difference in $\mathrm{Hz}$ and the spin coupling of 2.5 $(\Delta \vee / \mathrm{J}=36.6 / 14.5)$ and $10.1(\Delta \vee / \mathrm{J}=$ 133.8/13.3), respectively. Alliinase activity measurement using 5 as the substrate reveal that the enzyme possess an activity of 4.6 units/mg compare to 12 units/mg by using 4 as the substrate.

Fmoc-(+)-alliin (6) and (+)-DL-alliin methyl ester have also been synthesized to test the roles of amino and carboxyl groups in alliinase reaction. Compound 6 was synthesized by mixing $(+)$ alliin with FmocOSu. (+)-DL-alliin methyl ester was synthesized by mixing $(+)$ alliin with anhydrous methanol in acidic conditions. The $(+)$-alliin methyl ester produced contains both (+)-L-alliin methyl ester (7) and (+)-D-alliin methyl ester (8) due to racemization $[51,52]$. Instead of fractional crystallization in $95 \%$ ethanol, RP-HPLC is used to purify compounds 6 and (+)-DL-alliin methyl ester. Results show that compounds 6 and $(+)$ DL-alliin methyl ester are eluted at 18 and 4.6 min, respectively. Compound 6 and (+)-DL-alliin methyl ester are dried as a white powder with $76 \%$ yield of $>97 \%$ purity. Non-first-order correction is not needed to explain the pattern of the couplings for compounds 6 and (+)-DL-alliin methyl ester. The alliinase activity assay results of compounds 6 and (+)-DL-alliin methyl ester show that both compounds are inactive in alliinase enzymatic reaction. Alliinase belongs to the class of carbon-sulfur lyases named Salk(en)yl-L-cystene solfoxide lyase and catalyzes the cleavage of carbon-sulfur bond of S-allyl-Lcysteine sulfoxide in a beta-elimination/ deamination reaction involving an aminoacryl bound PLP-amino acrylate (Schiff's base) reaction intermediate $[45,47,53,54]$. Alliinase provides acidic and basic groups in the active site of the enzyme, inducing polarization of the $\mathrm{S}=\mathrm{O}$ group of the substrate, which initiates the carbon-sulfur bond breakage and produces an acrylamide bound PLP and allyl sulfenic acid. This catalytic mechanism is similar to that of cystathionine $\beta$-lyase [53]. Subsequently, the schiff's base of acrylamide bound PLP is spontaneously hydrolyzed and decomposed to pyruvate and ammonia. Simultaneously, condensation of two allyl sulfenic acids yields allicin. In agreement with this mechanism, it is plausible that the Fmoc group in Fmoc-alliin is blocking PLP cofactor binding and the inability to form carboxylate anion in (+)-alliin methyl ester inhibits the alliinase reaction. It is interesting to know that optimal $\mathrm{pH}$ value for alliinase catalytic activity is 6.5 , while the optimal temperature is $33^{\circ} \mathrm{C}$.

The in vitro cytotoxicity and anti-cancer effect of in situ allicin against Mus musculus colon carcinoma cells CT26.WT was determined by MTT assay [8]. Fig. 2 shows the $\mathrm{IC}_{50}$ doseresponse curve of in situ allcin on viability of Mus musculus colon carcinoma cells CT26.WT. Results show clear evidence of cytotoxicity of the in situ allicin against the CT26.WT in a dose dependent manner, compared to the controls (PBS, alliin, or alliinase). Shrinkage, granulation of cytoplasm, and detachment were visible in allicin treated cells. The half maximal inhibitory concentration $\left(\mathrm{IC}_{50}\right)$ is the dilution of either the alliin or allinase solution to produce fifty percent inhibition of cells in vitro. The $\mathrm{IC}_{50}$ of $11.24 \mathrm{mM}$ (+)-L-alliin solution is calculated to be 1:60 dilution measured by mixing diluted alliin with $0.58 \mu \mathrm{M}$ alliinase. The $\mathrm{IC}_{50}$ of $11.54 \mu \mathrm{M}$ alliinase solution is calculated to be $1: 630$ dilution measured by mixing diluted alliinase with 0.56 $\mathrm{mM}(+)$-L-alliin. Since $2 \mathrm{~mol}$ of alliin produces 1 $\mathrm{mol}$ of allicin in the allinase enzymatic reaction, the $\mathrm{IC}_{50}$ in term of allicin is $93.67 \mu \mathrm{M}$. Comparable results were obtained with AGE, allicin, and in situ allicin [8,9]. Time course results have revealed that $(+)$-L-alliin in culture medium is fully active for 3 days, but is then 
gradually declines until it is inactive after 7 days. Data also reveal that with high (+)-L-alliin concentrations, less alliinase is needed to reach the $50 \%$ viable cells and vice versa. The $I_{50}$ of $11.24 \mathrm{mM}(-)$-L-alliin solution is calculated to be $1: 19$ dilution. In addition, anti-cancer effect has been tested with Fmoc-(+)-alliin and (+)-DL-alliin methyl ester with negative results, which confirm that both compounds are inactive in alliinase enzymatic reaction.

Experimental data have indicated that allicin is responsible for the antimicrobial activity of AGE against a broader spectrum of microorganisms $[2,4,55,56]$. Allicin is also reported to be active against methicillin resistant human pathogen Staphylococcus aureus (MRSA) [38]. The fact that diallyl disulfide has a significantly lower antimicrobial activity indicates that the thiosulfinate group plays an important role in allicin's activity. In this study, the antibacterial activities of AGE, allcin, and in situ allcin against gram-positive Staphylococcus aureus subsp. aureus Rosenbach and gram-nagative Escherichia coli were measured using bacterial plate-diffusion growth inhibition assay (Fig. 3). Data show that the maximum zone of inhibition

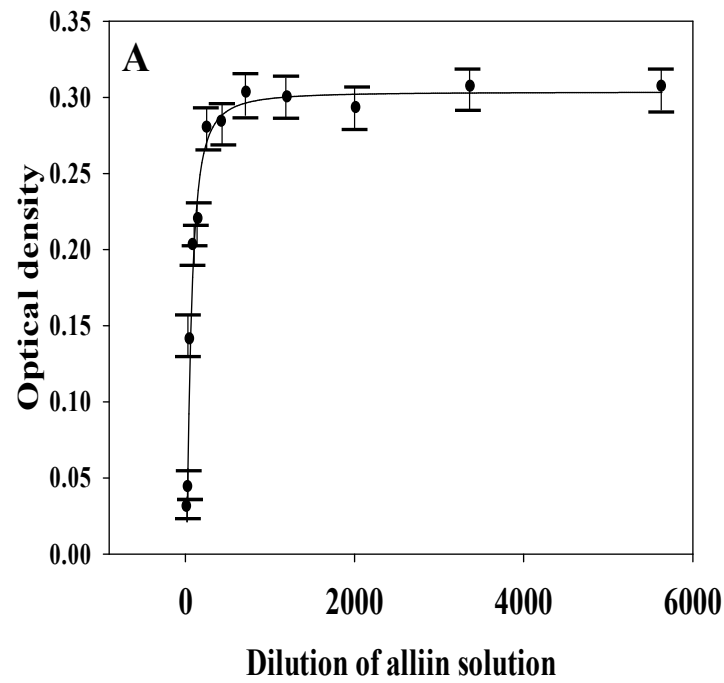

(39 mm) was observed in Staphylococcus aureus and the minimum $(17 \mathrm{~mm})$ was observed for Escherichia coli. PBS was used as a negative control. The lowest concentration at which there is no growth was reported as minimum inhibitory concentration (MIC). Results from the doseresponse study of allicin (data not shown) show that MICs were in the ranges of $56-140$ and 280-560 $\mu \mathrm{M}$ in Staphylococcus aureus and Escherichia coli, respectively. The in-situ allicin is as active as allicin purified from AGE or allicin synthesized chemically in a dose-dependent manner. It has been reported by Miron et al. [14] that allicin readily diffuses across the phospholipid membranes. The basis for antimicrobial activity of the majority of antibiotics, allicin and the non-plant-derived antibiotics penicillin, citrinin, gliotoxin, clavacin and pyocyanines is their ability to react with cysteine. When allicin penetrates the cell, it reacts with free thio groups indiscreetly [13-15]. In addition, it is known that the antimicrobial efficacy of AGE is time and temperature dependent $[7-9,57]$. This explains why allicin is effective in situ because alliin and alliinase are more stable and less reactive toward free thio groups [58].

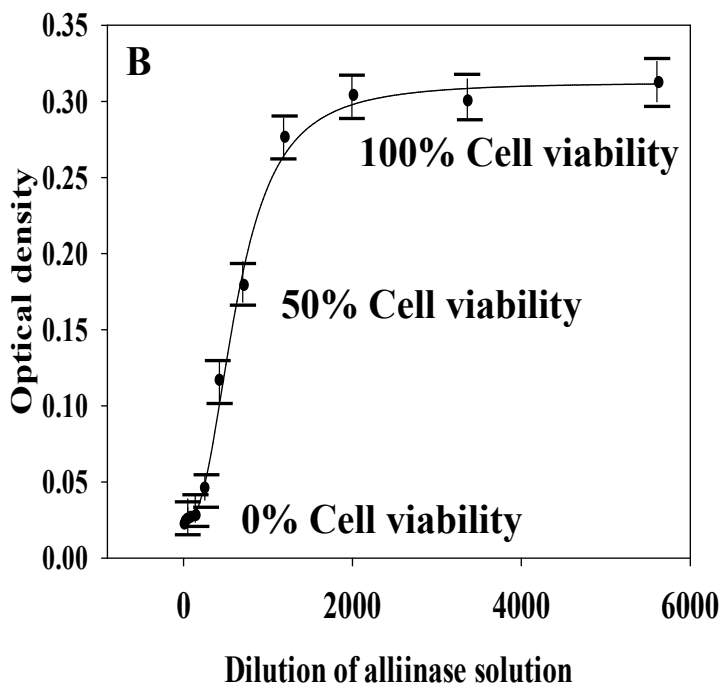

A, in situ allicin solution generated from different alliin concentrations with $0.58 \mu \mathrm{M}$ alliinase; $B$, in situ allicin solution generated from different alliinase concentrations with $0.56 \mathrm{mM}$ alliin

Fig. 2. Dose-response curve of viability of Mus musculuscolon carcinoma cells CT26.WT assessed by MTT assay 


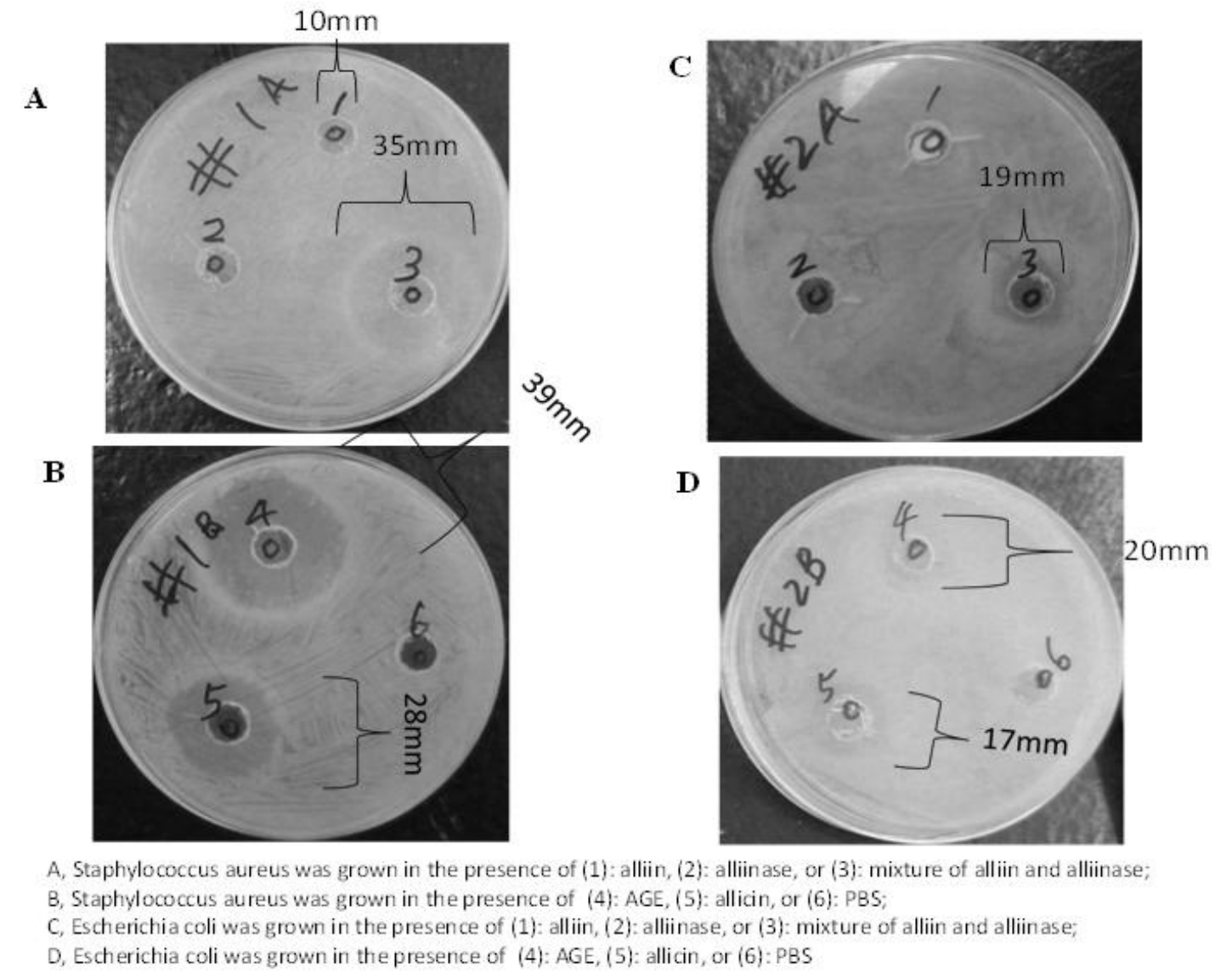

Fig. 3. Effect of alliin, alliinase, allicin, AGE, mixture of alliin and alliinase, or PBS on the growth of gram-positive Staphylococcus aureus subsp. aureus Rosenbach (ATCC ${ }^{\circledR} 6538^{\mathrm{TM}}$ ) or gram-nagative Escherichia coli (Migula) Castellani and Chalmers (ATCC ${ }^{\circledR} 8739^{\mathrm{TM}}$ ) by a bacterial plate-diffusion growth inhibition assay

Flow cytometric univariate analysis of cellular DNA content allows discrimination among sub$G_{1}, G_{1}, S$, and $G_{2} / M$ phase cells and is the simplest and most commonly used method to reveal the frequency of cells in these cell cycle phases [40]. The cells are fixed or permeabilized with a detergent and then stained with a nucleic acid-specific fluorophore such as propidium iodide (PI). Results of fluorescence measurements are displayed as a cellular DNA content frequency histogram, which shows the proportions of cells in particular phases of the cycle based on the fluorescence intensity. The content of cellular DNA in $G_{2}$ and $M$ phases have twice as much DNA as $G_{1}$ phase cells and $S$ phase cells have intermediate DNA content. Flow cytometry can measure DNA content of 5000 cells per second and trace the dynamic changes in cell cycle. During apoptosis, a portion of nuclear DNA may be lost from the cell in shedding apoptotic bodies and some fragmented DNA may be extracted during fixation and staining. Consequently, apoptotic cells are often distinguished on frequency histograms by a deficit in DNA content (sub-G $\mathrm{G}_{1}$ cells). The actual percentages of $G_{1}, S, G_{2} / M$, and sub- $G_{1}$ cells are obtained by deconvolution of the histograms using a PeakFit program. Fig. 4 shows DNA content frequency histograms of the effect of PBS, in situ allicin, or AGE on the cell cycle of Mus musculuscolon carcinoma cells CT26.WT. The data show a notable increase in sub- $G_{1}$ populations of the cell cycle on the cells treated with allicin, indicating the induction of apoptosis. This agrees with previous finding that allicin induces apoptosis in cancer cells [59]. Again the results show that in-situ allicin is as active as allicin purified from AGE or synthesized chemically. 


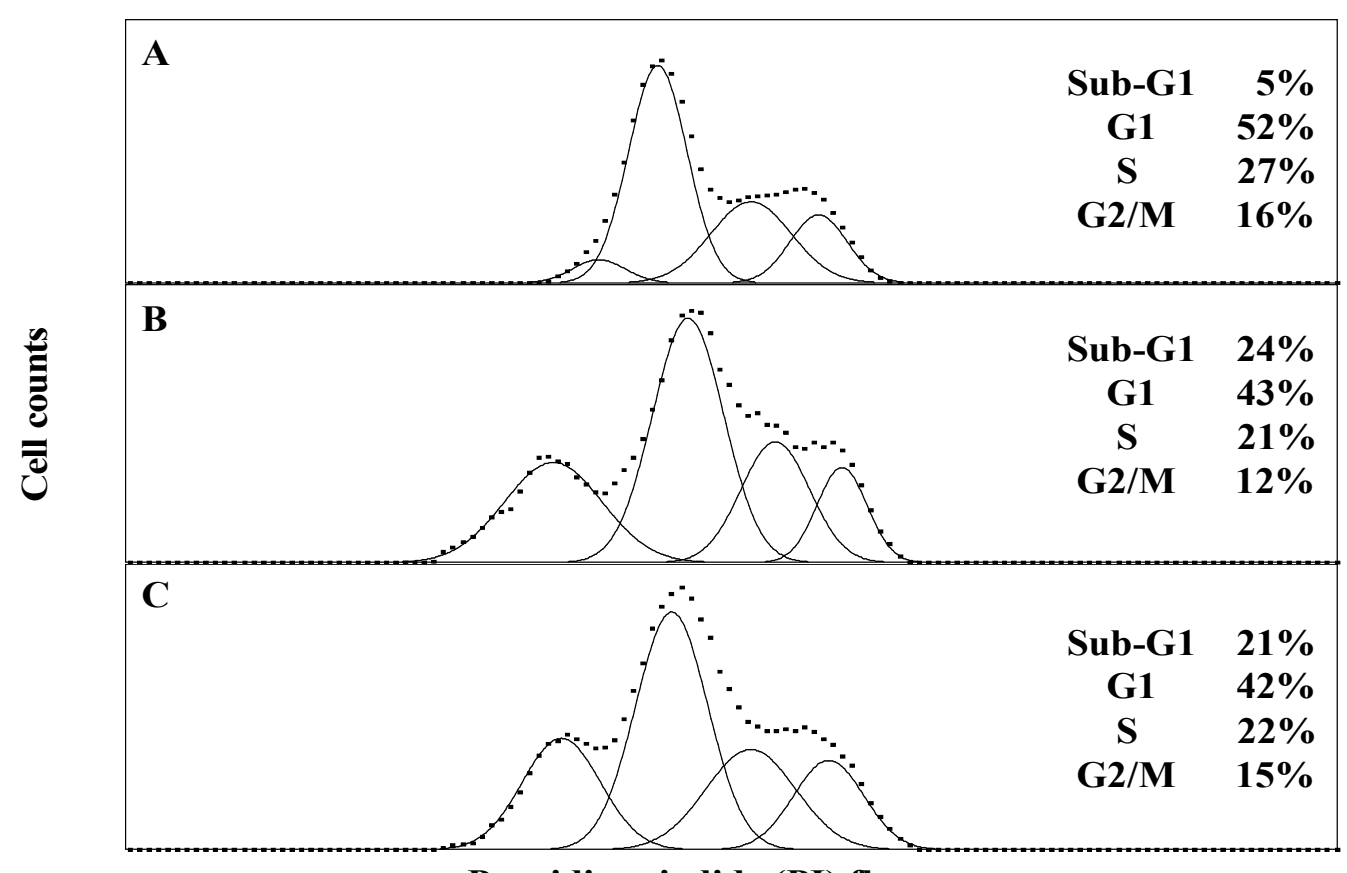

Propidium iodide (PI) fluorescence

A, $8 \mu \mathrm{L}$ of PBS was added into $200 \mu \mathrm{L}$ cell culture;

$\mathrm{B}, 1.5 \mu \mathrm{L}$ of alliin $(56.18 \mathrm{mM})$ and $8 \mu \mathrm{L}$ of alliinase $(11.54 \mu \mathrm{M})$ were added into $200 \mu \mathrm{L}$ cell culture;

C, $8 \mu \mathrm{L}$ of AGE was added into $200 \mu \mathrm{L}$ cell culture

Fig. 4. Flow cytometric analyses of the effect of PBS, in situ allicin, or aqueous garlic extract (AGE) on the cell cycle of Mus musculus colon carcinoma cells CT26.WT

\section{CONCLUSION}

We describe here a facile pathway to synthesize diastereomerically pure alliins and their conversion to allicin by enzymatic reaction of alliinase. Cancer cell viability assay MTT assay, bacterial plate-diffusion growth inhibition assay, and flow cytometry cell cycle analysis have been used to demonstrate the anti-cancerous/antipathogenic activities of the in-situ allicin. Protocols developed are simple and effective. Results demonstrate that the in-situ allicin is as active as allicin purified from AGE or allicin synthesized chemically in a dose-dependent manner. The data obtained here provide useful information on the design of the in-situ allicin strategy. Further research in modifying alliin structure (other substrates) and alliinase conjugated to a tumor targeting antibody against mouse cancer cells are also in progress.

\section{CONSENT}

The author hereby declares all experiments have been examined and approved by the appropriate ethics committee.

\section{ETHICAL APPROVAL}

It is not applicable.

\section{ACKNOWLEDGEMENTS}

Financial support from the Research Resources Center at UIC is gratefully acknowledged.

\section{COMPETING INTERESTS}

Authors have declared that no competing interests exist.

\section{REFERENCES}

1. Cavallito C, Bailey JH. Allicin, The antibacterial principle of Allium sativum. Isolation, physical properties and antibacterial action. J Am Chem Soc. 1944;66:1944-52.

2. Koch HP, Lawson LD. editors. Garlic: The science and therapeutic applications of Allium sativum $L$. and related species. Baltimore, USA: Williams \& Wilkins; 1996. 
3. Block E. Garlic and other alliums: The lore and the science. Cambridge, UK: The Royal Society of Chemistry; 2010.

4. Borlinghaus J, Albrecht F, Gruhlke $\mathrm{MCH}$, Nwachukwu ID, Slusarenko AJ. Allicin: chemistry and biological properties. Molecules. 2014;19:12591-618.

5. Blumenthal M. Herb sales down 7.4 percent in mainstream market. HerbalGram, USA: American Botanical Council; 2005.

6. Tapiero $\mathrm{H}$, Townsend DM, Tew KD. Organosulfur compounds from alliaceae in the prevention of human pathologies. Biomed Pharmacother. 2004;58:183-93.

7. Wang H, Li X, Liu X, Shen D, Qiu Y, Zhang $\mathrm{X}$, Song J. Influence of $\mathrm{pH}$, concentration, and light on stability allicin in garlic (Allium sativum L.) aqueous extract as measured by UPLC. J Sci Food Agric. 2014;95:1838-44.

8. Lee J, Gupta S, Huang J, Jayathilaka LP, Lee B. HPLC-MTT assay: Anti-cancer activity of aqueous garlic extract is from allicin. Anal Biochem. 2013;436:187-9.

9. Lee J, Gupta S, Huang J, Jayathilaka LP, Lee B. Preparation and purification of garlic-derived organosulfur compound allicin by green methodologies. In: Mohammad A, Inamuddin PM, editors. Green chromatographic techniques: separation and purification of organic and inorganic analytes. London, UK: Springer; 2013.

10. Lanzotti $V$. The analysis of onion and garlic. J Chromatogr A. 2006;1112:3-22.

11. Block $E$. The chemistry of garlic and onions. Sci Am. 1985;252:114-9.

12. Ichikawa M, Ide N, Yoshida J, Yamaguchi $\mathrm{H}$, Ono $\mathrm{K}$. Determination of seven organosulfur compounds in garlic by highperformance liquid chromatography. J Agric Food Chem. 2006;54:1535-40.

13. Rabinkov A, Miron T, Mirelman D, Wilchek M, Glozman S, Yavin E, Weiner L. Sallylmercaptoglutathione: The reaction product of allicin with glutathione possesses SH-modifying and antioxidant properties. Biochim Biophys Acta. 2000; 1499:144-53.

14. Miron T, Rabinkov A, Mirelman D, Wilchek $M$, Weiner $L$. The mode of action of allicin: its ready permeability through phospholipid membranes may contribute to its biological activity. Biochim Biophys Acta. 2000; 1463:20-30.
15. Freeman F, Kodera Y. Garlic chemistrystability of S-(2-propenyl) 2-propene-1sulfinothioate (allicin) in blood, solvents, and simulated physiological fluids. J Agric Food Chem. 1995;43:2332-38.

16. Cutler RR, Wilson P. Antibacterial activity of a new, stable, aqueous extract of allicin against methicillin-resistant Staphylococcus aureus. Br J Biomed Sci. 2004;61:71-4.

17. Miron T, Mironchik M, Mirelman D, Wilchek M, Rabinkov A. Inhibition of tumor growth by a novel approach: In situ allicin generation using targeted alliinase delivery. Mol Cancer Ther. 2003;2: 1295-301.

18. Arditti FD, Rabinkov A, Miron T, Reisner $Y$, Berrebi A, Wilchek M, Mirelman D. Apoptotic killing of B-chronic lymphocytic leukemia tumor cells by allicin generated in situ using a rituximab-alliinase conjugate. Mol Cancer Ther. 2005;4:325-32.

19. Fry $\mathrm{FH}$, Okarter $\mathrm{N}$, Baynton-Smith $\mathrm{C}$, Kershaw MJ, Talbot NJ, Jacob C. Use of a substrate/alliinase combination to generate antifungal activity in situ. J Agric Food Chem. 2005;53:574-80.

20. Stoll A, Seebeck E. Chemical investigations on alliin, the specific principle of garlic. Adv Enzymol. 1951;11: 377-400.

21. Miron $T$, Shin I, Feigenblat $G$, Weiner $L$, Mirelman D, Wilchek M, Rabinkov A. A spectrophotometric assay for allicin, alliin, and alliinase (alliin lyase) with a chromogenic thiol: reaction of 4mercaptopyridine with thiosulfinates. Anal Biochem. 2002;307:76-83.

22. Jayathilaka LP, Gupta S, Huang J, Lee J, Lee B. Preparation of (+)-trans-isoalliin and its isomers by chemical synthesis and RPHPLC resolution. J Biomol Tech. 2014;25: 67-76.

23. Iberl B, Winkler G, Muller B, Knobloch K. Quantitative determination of allicin and alliin from garlic by HPLC. Planta Med. 1990;56:320-6.

24. Lancaster JE, Kelly KE. Quantitative analysis of the S-alk(en)yl-L-cysteine sulphoxides in onion (Allium cepa L.). J Sci Food Agric. 1983;34:1229-35.

25. Corbi PP, Massabni AC, Moreira AG, Medrano FJ, Jasiulionis MG, Cost-Neto CM. Synthesis, characterization, and biological activity of a new palladium(II) complex with deoxyalliin. Can J Chem. 2005;83:104-9. 
26. Nikolić VD, Ilić DP, Nikolić LB, Stanković MZ, Stanojević LP, Savić IM. The synthesis and structure characterization of deoxyalliin and alliin. Advan Technol. 2012;1:38-46.

27. Yu TH, Wu CM, Rosen RT, Hartman TG, Ho CT. Volatile compounds generated from thermal degradation of alliin and deoxyalliin in an aqueous solution. J Agric Food Chem. 1994;42:146-53.

28. Stoll A, E. Seebeck E. Die synthese des naturlichen Alliins und seiner drei optisch aktiven isomeren. Helv Chim Acta. 1951; 34:481-7.

29. Koch I, Keusgen M. Diastereoselective synthesis of alliin by an asymmetric sulfur oxidation. Pharmazie. 1998;53:668-71.

30. Lajoie G, Crivici A, Adamson JG. A simple convenient synthesis of $\omega$-tert-butyl ester of Fmoc-aspartic and Fmoc-glutamic acids. Synthesis. 1990;571-2.

31. Gawande MB, Branco PS. An efficient and expeditious Fmoc protection of amines and amino acids in aqueous media. Green Chem. 2011;13:3355-9.

32. Wehner JW, Lindhorst TK. SFluorenylmethyl protection of the cysteine side chain upon $\mathrm{Na}-\mathrm{Fmoc}$ deprotection. Beilstein J Org Chem. 2012;8:2149-55.

33. Mönch S, Rychlik M. Improved folate extraction and tracing deconjugation efficiency by dual label isotope dilution assays in foods. J Agric Food Chem. 2012; 60:1363-72.

34. Kowalak JA, Walsh KA. P-Methylthioaspartic acid: Identification of a novel posttranslational modification in ribosomal protein S12 from Escherichia coli. Prot Sci. 1996;5:1625-32.

35. Kim TY, Brun YV, Reilly JP. Effects of tryptic peptide esterification in MALDI mass spectrometry. Anal Chem. 2005;77: 4185-93.

36. Ilić DP, Nikolić VD, Nikolić LB, Stanković MZ, Stanojević LP. Thermal degradation, antioxidant and antimicrobial activity of the synthesized allicin and allicin incorporated in gel. Hem Ind. 2010;64:85-91.

37. Fujisawa $\mathrm{H}$, Watanabe $\mathrm{K}$, Suma $\mathrm{K}$, Origuchi K, Matsufuji H, Seki T, Ariga T. Antibacterial potential of garlic-derived allicin and its cancellation by sulfhydryl compounds. Biosci Biotechnol Biochem. 2009;73:1948-55.

38. Cutler RR, Wilson P. Antibacterial activity of a new, stable, aqueous extract of allicin against methicillin-resistant
Staphylococcus aureus. Br J Biomed Sci. 2004;61:71-4.

39. Zaidan MR, Noor Rain A, Badrul AR, Adlin A, Norazah A, Zakiah I. In vitro screening of five local medicinal plants for antibacterial activity using disc diffusion method. Tropical Biomedicine. 2005;22: 165-70.

40. Darzynkiewicz Z, Bedner E, Smolewski P. Flow cytometry in analysis of cell cycle and apoptosis. Semin Hematol. 2001;38: 179-93.

41. Kuettner EB, Hilgenfeld R, Weiss MS. Purification, characterization, and crystallization of alliinase from garlic. Arch Biochem Biophys. 2002;402:192-200.

42. $\mathrm{He} \mathrm{Q}$. The alliinase and lachrymatory factor synthase systems in Petiveria alliacea (Doctoral Dissertation, University of Albany, NewYork), Ann Harbor, USA; UMI Dissertation Publishing; 2010.

43. Krest I, Keusgen M. Stabilization and pharmaceutical use of alliinase. Pharmazie. 1999;54:289-93.

44. Rabinkov A, Wilchek M, Mirelman D. Alliinase (alliin lyase) from garlic (allium sativum) is glycosylated at Asn146 and forms a complex with a garlic mannosespecific lectin. Glycocon J. 1995;12:690-8.

45. Musah RA, He Q, Kubec R, Jadhav $A$. Studies of a novel cysteine sulfoxide lyase from Petiveria alliacea: The first heteromeric alliinase. Plant Physiol. 2009; 151:1304-16.

46. Mallika T, Omer E, Lianfu Z. Separation and purification of alliinase and alliin from garlic (Allium sativum). J Acad Indus Res. 2014;2:599-605.

47. Manabe T, Hasumi A, Sugiyama M, Yamazaki M, Saito K. Alliinase [Salk(en)yl-L-cysteine sulfoxide lyase] from Allium tuberosum (Chinese chive) Purification, localization, cDNA cloning and heterologous functional expression. Eur J Biochem. 1998;257:21-30.

48. Weik R, Franky A, Striedner G, Raspor P, Bayer K, Mattanovich D. Recombinant expression of alliinase lyase from garlic (Allium sativum) in bacteria and yeasts. Planta Med. 1998;64:387-8.

49. Wu X, Zhang T, Bian J, Xu J. Cloning of alliinase gene from garlic bulb and its expression in Pichia pastoris. Chin Trad Herb Drugs. 2012;43:143-7.

50. Crews P, Rodriguez J, Jaspars M. Organic Structure Analysis. $2^{\text {nd }}$ ed. New York: Oxford University Press; 2009. 
51. Li J, Sha Y. A convenient synthesis of amino acid methyl esters. Molecules. 2008;13:1111-9.

52. Smerdka J, Rademann J, Jung G. Polymer-bound alkyltriazenes for mild racemization-free esterification of amino acid and peptide derivatives. J Peptide Sci. 2004;10:603-11.

53. Ravilious GE, Jez JM. Structural biology of plant sulfur metabolism: From assimilation to biosynthesis. Nat Prod Rep. 2012:29: 1138-52.

54. Nock LP, Mazelis M. The C-S lyases of higher plants: direct comparison of the physical properties of homogeneous alliin lyase of garlic (Allium sativum) and onion (Allium cepa). Plant Physiol. 1987;85: 1079-83.

55. Cañizares P, Gracia I, Gómez LA, García A, De Argila CM, Boixeda D, De Rafael L. Thermal degradation of allicin in garlic extracts and its implication on the inhibition of the in vitro growth of Helicobacter pylori. Biotechnol Prog. 2004;20:32-7.
56. Hughes B, Lawson L. Antimicrobial effects of Allium sativum L. (garlic), Allium ampeloprasum L. (elephant garlic), and Allium cepa L. (onion), garlic compounds and commercial garlic supplement products. Phytother Res. 1991;5:154-8.

57. Durairaj S, Srinivasan S, Lakshmanaperumalsamy P. In vitro antibacterial activity and stability of garlic extract at different $\mathrm{pH}$ and temperature. Elec J Biol. 2009;5:5-10.

58. Appel E, Vallon-Eberhard A, Rabinkov A, Brenner O, Shin I, Sasson K, Shadkchan $\mathrm{Y}$, Osherov N, Jung S, Mirelman D. Therapy of murine pulmonary Aspergillosis with antibody-alliinase conjugates and alliin. Antimicrob Agents Chemother. 2010; 54:898-906.

59. Oommen S, Anto RJ, Srinivas G, Karunagaran D. Allicin (from garlic) induce caspase-mediated apoptosis in cancer cells. Eur J Pharmacol. 2004;485:97-103.

(c) 2015 Gupta et al.; This is an Open Access article distributed under the terms of the Creative Commons Attribution License (http://creativecommons.org/licenses/by/4.0), which permits unrestricted use, distribution, and reproduction in any medium, provided the original work is properly cited.

\section{Peer-review history:}

The peer review history for this paper can be accessed here: http://sciencedomain.org/review-history/10162 